\title{
Pigment Epithelium-Derived Factor Supports Normal Development of Photoreceptor Neurons and Opsin Expression after Retinal Pigment Epithelium Removal
}

\author{
Monica M. Jablonski, ${ }^{1}$ Joyce Tombran-Tink, ${ }^{2}$ David A. Mrazek, ${ }^{2}$ and Alessandro lannaccone ${ }^{1}$ \\ ${ }^{1}$ Retinal Degeneration Research Center, Department of Ophthalmology, University of Tennessee, Memphis, Memphis, \\ Tennessee 38163, and 2Center for Neuroscience Research, Children's National Medical Center, Washington, DC 20010
}

Dysfunction of the retinal pigment epithelium (RPE), its loss, or separation from the underlying neural retina results in severe photoreceptor degeneration. Pigment epithelium-derived factor (PEDF) is a glycoprotein with reported neuroprotective and differentiation properties that is secreted in abundance by RPE cells. The "pooling" of PEDF within the interphotoreceptor matrix places this molecule in a prime physical location to affect the underlying neural retina. The purpose of this study was to analyze the morphogenetic activity of PEDF in a model of photoreceptor dysmorphogenesis induced by removal of the RPE. Eyes were dissected from embryonic Xenopus laevis, and the RPE was removed before culturing in medium containing PEDF, PEDF plus anti-PEDF antibodies, or medium alone. Control retinas were maintained with an adherent RPE. Light and electron microscopic analysis was used to examine retinal ultrastructure. Opsin was localized immunocytochemically and quantified as an index of outer segment membranous material and photoreceptor protein expression. Removal of the RPE resulted in an aberrant assembly of photoreceptor outer segments, loss of fine subcellular ultrastructure in photoreceptors, and a reduction in opsin protein levels when compared with control retinas. The addition of PEDF prevented the dysmorphic photoreceptor changes induced by RPE removal. In particular, photoreceptor ultrastructure, outer segment membrane assembly, and steady-state levels of opsin were equivalent to control conditions. Anti-PEDF antibodies completely blocked the morphogenetic activity of PEDF. These results indicate that PEDF is able to mimic the supportive role of the RPE on photoreceptors during the final stages of retinal morphogenesis.

Key words: photoreceptor; pigment epithelium-derived factor; retinal dysmorphogenesis; neuroprotection; ultrastructure; protein expression
The importance of an intact and fully functional retinal pigment epithelium (RPE) on photoreceptor development and survival has been known for many years. During development the rudimentary layers that will become the RPE and the retina are brought into close proximity upon the collapse of the optic vesicles, establishing an early relationship between these two tissues. At this developmental stage the retina is undifferentiated morphologically and photoreceptor outer segments have not yet formed, thus raising the possibility that the RPE could be a source of signals that induce or regulate photoreceptor development and outer segment elaboration. Also, the observation that outer segment development is impaired in the absence of the RPE in most species suggests that interactions between these two cell types may be of fundamental importance for the structural and functional differentiation of photoreceptors (Hollyfield and Witkovsky, 1974).

In a mature retina the photoreceptor outer segments degenerate very quickly after physical separation from the RPE, and the degree of recovery is negatively correlated with the duration of the detachment (Erickson et al., 1983; Anderson et al., 1986; Guérin et al., 1989, 1993; Lewis et al., 1991). In the Royal College of Surgeons (RCS) rat a defect in the RPE gene Mertk (D'Cruz et al.,

\footnotetext{
Received May 31, 2000; accepted July 13, 2000.

This study was supported by National Eye Institute Grant EY10853 (M.M.J.), an unrestricted departmental grant from Research to Prevent Blindness, New York, and a grant from the University of Tennessee Medical Group (M.M.J.). M.M.J. is a Research to Prevent Blindness William and Mary Greve Special Scholar. We gratefully acknowledge Drs. Marshall J. Graney and Elizabeth A. Tolley, University of Tennessee, Memphis, Department of Preventive Medicine, Division of Biostatistics and Epidemiology, for their assistance with the statistical evaluation of our data. We also acknowledge the technical assistance of Amira Wohabrebbi and Cynthia Ervin. The following have generously provided antibodies for our use: Dr. Paul A. Hargrave, University of Florida, Gainesville, FL, and Dr. James F. McGinnis, Dean A. McGee Eye Institute, Oklahoma City, OK.

Correspondence should be addressed to Dr. Monica M. Jablonski, Department of Ophthalmology, University of Tennessee, Memphis, 956 Court Avenue, Memphis, TN 38163. E-mail: mjablonski@mail.eye.utmem.edu.

Copyright (C) 2000 Society for Neuroscience $0270-6474 / 00 / 207149-09 \$ 15.00 / 0$
}

2000) results in photoreceptor degeneration unless growth factors are injected into the subretinal space (Faktorovich et al., 1990) or an RPE transplant is performed (Li and Turner, 1991). In all cases the rescue extends beyond the limits of the injection or transplant, suggesting that a diffusible factor is responsible for photoreceptor rescue. Moreover, it has been demonstrated that RPE-secreted proteins positively influence photoreceptor survival (Gaur et al., 1992; Sheedlo et al., 1992, 1998). Although an abundance of data indicates that the RPE or "factors" supplied by the RPE are of paramount importance to the development and/or survival of photoreceptors, the nature of these interactions is poorly understood.

Recent findings have identified disease-causing mutations in RPE-expressed genes in several forms of retinopathies. For example, mutations cosegregating with disease manifestations have been found in the RPE65 (Gu et al., 1997; Marlhens et al., 1997) and the cellular retinaldehyde-binding protein genes (Maw et al., 1997). The gene for pigment epithelium-derived factor (PEDF) has been tightly linked to the RP13 locus on chromosome 17, implicating it as a candidate gene for this form of autosomal dominant retinitis pigmentosa (Tombran-Tink et al., 1994; Goliath et al., 1996). PEDF is an RPE-secreted glycoprotein that binds to the glycosaminoglycans of the interphotoreceptor matrix (Tombran-Tink et al., 1995; Wu et al., 1995), placing this molecule in a prime physical location to affect the underlying neural retina.

Numerous studies support the role of PEDF in neuronal development, differentiation, and survival (Taniwaki et al., 1995, 1997; Araki et al., 1998; Bilak et al., 1999; DeCoster et al., 1999). However, the direct effect of PEDF on retinal photoreceptors has not yet been evaluated, nor has the potential role of PEDF as a neuroprotective agent in retinal dysmorphogenesis been elucidated. The purpose of the present study was to evaluate the efficacy of PEDF to protect against aberrant photoreceptor development because of RPE removal. Herein we have demonstrated for the first time that exogenous PEDF specifically prevented the dysmorphic morphological and protein expression changes that are induced by 
RPE removal. In particular, photoreceptor ultrastructure, outer segment membrane assembly, and opsin protein expression were equivalent to retinas that completed morphogenesis with an attached RPE. These results strongly support the role of PEDF in retinal morphogenesis. Our results also suggest that PEDF may offer new therapeutic strategies in the treatment of retinal detachment and other degenerations that are induced by dystrophies of the RPE.

\section{MATERIALS AND METHODS}

Preparation of purified PEDF and anti-PEDF. PEDF was isolated and purified form bovine interphotoreceptor matrix by ionic exchange and gel filtration chromatography, as previously described (Tombran-Tink et al., 1991). Briefly, soluble bovine interphotoreceptor matrix was extracted from fresh bovine eyes by a gentle lavage of the eyecup after careful removal of the anterior segment and vitreous. A volume of $0.5 \mathrm{ml}$ of ice-cold PBS, pH 7.4, was used in this procedure. Washes from 100 eyecups were pooled, centrifuged, and filtered using a $0.2 \mu \mathrm{M}$ Nalgene filtration unit. Approximately $500 \mathrm{ml}$ of the interphotoreceptor matrix wash was applied to a Beckman Altex TSK column equilibrated with $10 \mathrm{~mm}$ sodium phosphate, $\mathrm{pH} 7.2$. Bound PEDF was eluted with $0.5 \mathrm{M} \mathrm{NaCl}$ at a flow rate of $8 \mathrm{ml} / \mathrm{min}$. Absorbance was monitored at 280 and $260 \mathrm{~nm}$. Fractions containing the PEDF were combined, and the protein concentration was determined by a Bio-Rad assay (Hercules, CA). The pooled fractions were concentrated and subsequently were purified by using a Sephadex G-250 column. Eluates containing PEDF were separated electrophoretically on a $10 \%$ SDS gel and stained with Coomassie blue.

Polyclonal antibodies were generated against bovine PEDF. In brief, 5 $\mathrm{mg}$ of the purified protein was used to inject rabbits prepared for antibody production in the Laboratory of Dr. James F. McGinnis (Dean McGee Eye Institute, Oklahoma City, OK). Three injections of $\sim 0.5 \mathrm{mg}$ were given to each rabbit over a period of 6 weeks. Serum obtained from each immunized animal was tested 2 weeks after each injection. Preimmunized serum from each animal also was analyzed. Samples containing the purified 50 $\mathrm{kDa}$ PEDF protein were pooled and used in Western blot analysis to determine the specificity of the polyclonal antibodies for the purified PEDF protein. Serum from rabbit 513B yielded the highest degree of specificity; therefore, this antibody was used in all of the analyses presented herein. Additional Western procedures were performed to determine the specificity of the 513B anti-PEDF antibody for Xenopus laevis PEDF.

Retinal culture conditions. The handling of Xenopus laevis was in accordance with the Declaration of Helsinki and The Guiding Principles in the Care and Use of Animals (DHEW Publication 80-23, National Institutes of Health). The experimental culture preparation that uses Xenopus embryonic eyes has been described previously (Hollyfield and Witkovsky, 1974; Lolley et al., 1977; Stiemke and Hollyfield, 1994, 1995; Jablonski et al., 1999). Adult frogs were induced to breed with injections of human chorionic gonadotropin (Sigma, St. Louis, MO). The external staging system of Nieuwkoop and Faber (1956) was used to determine retinal maturity. Embryos and isolated retinas were maintained under cyclic lighting conditions (12 hr light/dark). In all experiments the eyes were removed from embryos at stage $33 / 34$, just as photoreceptor outer segments are beginning to be elaborated (Stiemke et al., 1994). At this stage the eye rudiments are not yet surrounded by the sclera, leaving the posterior segment coated only by the RPE layer. Taking advantage of this characteristic, we gently peeled away the overlying RPE from the neuroepithelium, leaving the underlying retina exposed to the culture medium. Intact eye rudiments without an adherent RPE were cultured in Niu-Twitty medium alone (Jacobson, 1967), Niu-Twitty containing purified PEDF, or PEDF plus anti-PEDF antibodies (513B). Control eyes were allowed to mature in vitro in the presence of an adherent RPE in Niu-Twitty medium alone (i.e., no PEDF was added). Eye rudiments were maintained in vitro for $3 \mathrm{~d}$ at $23^{\circ} \mathrm{C}$ after which they were fixed or frozen as appropriate for the subsequent analysis. With this culture protocol (removal at stage 33/34 and maintenance for 3 d at $23^{\circ} \mathrm{C}$ ) retinas from fully intact eye rudiments have reached approximately stage 42 of the in vivo developmental scale, characterized by complete stratification of the retina and mature photoreceptors with well developed outer segments that express opsin and $r d s /$ peripherin in the proper location and amount (Hollyfield and Rayborn, 1979; Stiemke et al., 1994; Jablonski et al., 1999)

Morphological assessment. After $3 \mathrm{~d}$ of in vitro development the eye rudiments were grossly examined under a dissecting microscope for integrity and smoothness of the neuroepithelial or RPE surface. Any retina that exhibited an uneven surface or had many loose cells associated with it was discarded. For ultrastructural analysis the eyes were fixed in Tucker fixative ( $2 \%$ glutaraldehyde and $1 \%$ osmium tetroxide), dehydrated, and embedded in Araldite/EMbed812 (Electron Microscopy Sciences, Fort Washington, PA). To ensure that photoreceptors of equivalent stages of maturation were compared, we performed structural analyses on tissue sections taken exclusively from the posterior pole region of the retina. Sections $1 \mu \mathrm{m}$ thick were cut, stained with toluidine blue O, and examined on a Nikon Eclipse E800 microscope equipped with Sensys Color Camera (Photometrics, Tucson, AZ). Images were collected with MetaMorph Imaging System software (Universal Imaging, West Chester, PA). For ultrastructural analyses thin sections were cut, placed on 200 mesh copper grids, and viewed on a JEOL 2000 electron microscope.

An initial series of experiments was undertaken to evaluate at the light microscopic level the ability of various concentrations of PEDF and antiPEDF to support outer retinal morphogenesis in the absence of the RPE and to block the morphogenetic properties of PEDF, respectively. The main criterion for evaluation of the protective effect of PEDF was that of organized assembly of nascent outer segments that were elaborated in the absence of an attached RPE. The following concentrations were evaluated: 50,100 , and $500 \mathrm{ng} / \mathrm{ml}$ of PEDF and 1:500 and 1:1000 dilutions of anti-PEDF antibody. Detailed morphological and protein analyses subsequently were performed on additional retinas that were exposed to the following culture conditions: Niu-Twitty medium containing $50 \mathrm{ng} / \mathrm{ml}$ of PEDF, the empirically determined optimal concentration that allowed for elaboration of highly structured photoreceptor outer segments in the absence of the RPE; and $50 \mathrm{ng} / \mathrm{ml}$ of PEDF plus 1:500 dilution of antiPEDF antibody, the condition that was determined experimentally to prevent the permissive effect of PEDF on photoreceptor outer segment organization. The addition of 1:500 normal rabbit serum to the medium containing $50 \mathrm{ng} / \mathrm{ml}$ of PEDF was evaluated as a control to evaluate the ability of nonimmune serum to block PEDF-induced photoreceptor cytomorphogenesis.

The degree of outer segment organization was evaluated subjectively by using a grading scale similar to that which we have used previously (Stiemke and Hollyfield, 1994, 1995). Based on our previous experience using an identical in vitro assay to assess the ability of various factors to promote photoreceptor cytomorphogenesis in the absence of the RPE (Stiemke and Hollyfield, 1994, 1995; Stiemke et al., 1994; Jablonski et al., 1999; Kancherla et al., 1999; Jablonski and Ervin, 2000), the structure of individual photoreceptors within a retina can range from complete absence of outer segment material or many whorls of membrane (i.e., in retinas maintained without an RPE in Niu-Twitty medium) to highly structured outer segments with a cylindrical profile and no whorls of membrane (i.e., in retinas maintained with an intact RPE in Niu-Twitty medium). It is also possible that a single retina can contain photoreceptors of varying degrees of organization. To account for the degree of variability in outer segment organization that can occur, we refined our original grading scale and expanded it to include six levels of organization. The scale used in the present study included a grade of -1 that denotes a complete absence of outer segment membranous material. Outer segments, when present, received a grade ranging from 0 , which reflects a complete lack of organized structure of outer segment membranes $(0 \%$ organized or only whorls of membrane are present), to 4 , which describes $100 \%$ organization of all membranous material from a single photoreceptor. Each step of one grade reflects a $25 \%$ linear change in the level of organization. For each experimental condition eight contiguous photoreceptors from three individual retinas $(n=24)$ were evaluated with this scale. The total number of graded photoreceptors was 96 . The grader was blinded to the experimental condition under which each graded micrograph was obtained.

Immunocytochemistry. For immunocytochemical analyses the eyes were fixed in Davidson fixative (32\% ethanol, $2 \%$ formalin, and $11 \%$ acetic acid), followed by dehydration in ethanol. Eyes were embedded in Unicryl (Electron Microscopy Sciences). Sections $1 \mu \mathrm{m}$ thick were cut from the posterior pole region of the retina and collected on microscope slides that were coated previously with Biobond (Electron Microscopy Sciences). Sections were incubated in $5 \%$ goat serum (Vector Laboratories, Burlingame, CA) in PBS, rinsed in PBS, and incubated overnight in primary antibody at $4^{\circ} \mathrm{C}$ [anti-opsin; B630N (Röhlich et al., 1989) at 1:2000 dilution]. Gold-conjugated goat anti-mouse secondary antibodies were applied to the tissue sections (1:50 dilution for $2 \mathrm{hr}$, ultrasmall gold particle size) followed by silver enhancement, as described by the manufacturer (Electron Microscopy Services). Controls included the absence of primary antibody. Retinal sections were viewed on a Nikon Eclipse E800 microscope equipped with Sensys Color Camera (Photometrics), and images were collected by using MetaMorph Imaging System software (Universal Imaging). Two images were collected of each retinal section: a bright-field image that shows the morphology of the tissue and another image taken with epipolarized light that shows only the immunolabeling pattern. The epipolarized image was color-enhanced and merged with the bright-field image so that the specific immunolabeling patterns could be distinguished easily. Three eyes from each experimental condition were evaluated in this series of experiments.

Quantitation of opsin. Opsin is the most abundant photoreceptor protein, composing $\sim 80-90 \%$ of the total rod outer segment protein (Papermaster and Dreyer, 1974), thus making it an ideal candidate to assess the amount of outer segment membranous material present and overall photoreceptor protein expression levels. Opsin is localized to the lamellar portion of outer segment discs and the surrounding plasma membrane. To quantify the steady-state levels of opsin, we collected three sets of 10 eyes under each condition, ground them, and solubilized them with sodium cholate detergent (Sigma). Pooling of 10 retinas was necessary because of the small size of each individual intact eye rudiment (i.e., $\sim 100-150 \mu \mathrm{m}$ in diameter and $\sim 25 \mu \mathrm{g}$ of total protein per eye). Extracted proteins were applied in duplicate to Hybond-P membrane (Amersham Pharmacia Biotech, Buckinghamshire, England) by using a slot blot apparatus (Bio-Rad). After solubilization and dilution the amount of total protein per slot was $\sim 25-30$ 


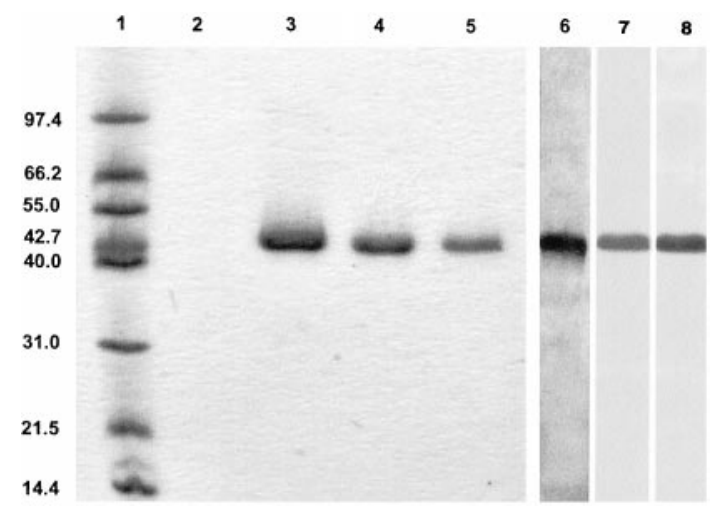

Figure 1. Migration of purified PEDF as a $50 \mathrm{kDa}$ molecular weight species on $10 \%$ SDS polyacrylamide gel detected by Coomassie blue staining. Molecular weight markers (Promega midrange standards) are shown in lane 1. Lane 2 is intentionally left blank. Lanes 3, 4, and 5 represent the purified PEDF protein at concentrations of 505, 252, and $126 \mathrm{ng}$, respectively. Lane 6 represents the Western blot analysis showing a very specific interaction, at $\sim 50 \mathrm{kDa}$, between $100 \mathrm{ng}$ of purified PEDF and the polyclonal PEDF antibody at 1:1000 dilution. Lanes 7 and 8, respectively, represent anti-PEDF (1:1000 dilution) applied to Xenopus retinal homogenates and Xenopus retinal homogenates with the addition of $100 \mathrm{ng}$ of purified PEDF.

$\mu \mathrm{g} / \mathrm{cm}^{2}$, which is well within the binding capacity of the Hybond-P membrane (maximum protein binding capacity of $125 \mu \mathrm{g} / \mathrm{cm}^{2}$ ). Blots were blocked in Blotto (5\% in PBS) for $1 \mathrm{hr}$, followed by incubation in primary antibody overnight at $4^{\circ} \mathrm{C}$ [anti-opsin; B630N (Röhlich et al., 1989) at 1:10,000 dilution]. The ECF Western blotting kit (Amersham Pharmacia Biotech) was used according to the manufacturer's protocols. Blots were scanned on a Storm 860 Imaging system (Molecular Dynamics, Sunnyvale, $\mathrm{CA}$ ), and data were quantified with ImageQuant software version 1.1 (Molecular Dynamics). An evaluation of standard curves indicates that this assay methodology is able to generate a linear fit of sample dilutions over a minimum of two log units of protein concentration and also that a $50 \%$ reduction in the concentration of opsin applied to the Hybond-P membrane is equivalent to a reduction of $\sim 45 \%$ in the level of chemiluminescent signal that is detected (data not shown). For each of the repetitions the data were normalized to the values obtained for eyes maintained with an intact RPE.

Statistical analyses. Photoreceptor outer segment grading data and steady-state opsin levels were analyzed statistically by one-way ANOVA, using SAS statistical software (SAS Institute, Cary, NC). Because graded photoreceptors were analyzed in groups of eight from three separate eyes under each experimental condition, observations within each eye could not be considered independent. To account for this, we calculated the average grading for each eye and conducted comparisons among groups only on the averages of each of the 12 eyes that were analyzed. Average steady-state opsin levels for each group of 10 eyes under the four experimental conditions were obtained as described above $(n=12$ also in this case) Preplanned comparisons were performed between each experimental condition for a total of six comparisons for each investigated variable (i.e., photoreceptor organization and opsin steady-state levels). This is in excess of the number of comparisons allowed before an adjustment of the experimental error rate alpha is required (Sokal and Rohlf, 1995). Therefore, to minimize the risk of type I error caused by repeated comparisons, the alpha level of 0.05 was adjusted by means of the Dunn-Sidák method as described in Sokal and Rohlf (1995). In so doing, only $p$ values $<0.009$ were considered statistically significant.

\section{RESULTS}

\section{Determination of optimal concentrations of PEDF and blocking antibody}

The preparation of bovine PEDF was highly purified, yielding single Coomassie blue-stained bands of $\sim 50 \mathrm{kDa}$ after electrophoretic separation (Fig. 1, lanes 3-5). Western blot analysis indicated that the polyclonal anti-PEDF recognizes purified bovine PEDF (Fig. 1, lane 6). In addition, the anti-PEDF antibody bound to a single $50 \mathrm{kDa}$ molecular species band in Xenopus retinal homogenates and also in Xenopus retinal homogenates to which purified PEDF was added before Western blot analysis (Fig. 1, lanes 7,8 , respectively).
Light microscopic evaluation of outer retinal structure revealed that, in the presence of an adherent RPE, outer segment membranes were highly organized and were composed of individual, stacked, flattened membranous saccules with a continuous profile (Fig. 2a). Retinas cultured in the absence of the RPE in Niu-Twitty medium contained photoreceptors with outer segments characterized by many whorls of membrane interspersed with packets of stacked discs (Fig. 2b). The addition of $50 \mathrm{ng} / \mathrm{ml}$ of PEDF to retinas maintained without an adherent RPE optimally supported the assembly of outer segments into stacked, flattened membranous saccules (Fig. 2c), which morphologically resembled those of photoreceptors that underwent morphogenesis in the presence of an adherent RPE cell layer (compare with Fig. 2a). Concentrations of PEDF $>50 \mathrm{ng} / \mathrm{ml}$ did not stimulate the same level of outer segment organization in the absence of the RPE. In retinas that were exposed to 100 and $500 \mathrm{ng} / \mathrm{ml}$ of PEDF, the majority of photoreceptors had many whorls of membranous discs in and among areas of organized outer segment (Fig. 2d,e, respectively). Structural analysis also revealed that a 1:500 dilution of nonimmune serum was unable to block the morphogenetic properties of PEDF (Fig. $2 f$ ). Anti-PEDF antiserum when diluted 1:1000 was able to partially prevent the dramatic improvement in outer segment organization that was promoted by $50 \mathrm{ng} / \mathrm{ml}$ of PEDF (Fig. $2 g$ ). However, a 1:500 dilution of antiserum was able to block almost completely the permissive and protective effects of $50 \mathrm{ng} / \mathrm{ml}$ of PEDF (Fig. $2 h$ ).

\section{Photoreceptor ultrastructure and grading of outer segment organization}

Figure $3 a$ shows an example of photoreceptors from retinas that were maintained with an adherent RPE. An evaluation of photoreceptor ultrastructure revealed outer segments that were composed of an array of highly organized, flattened, stacked membranous saccules that were in alignment with a corresponding inner segment. Calycal processes, budding from the inner segment, closely abutted the proximal outer segment region. The RPE was juxtaposed to the tips of the outer segments, and apical RPE processes surrounded the outer portions of the outer segments. Figure $3 b$ illustrates the effects of RPE removal on photoreceptor morphology. Removal of the RPE dramatically altered the ultrastructure of the photoreceptors. After $3 \mathrm{~d}$ of in vitro maturation in the absence of the RPE the photoreceptor outer segments were grossly dysmorphic and did not comprise an orderly assemblage of membranous discs. Rather, discs of uneven lengths were elaborated, some much shorter than the width of the inner segment and others much longer. Other areas of membranous whorls were found in what would be the subretinal space. The membranous outer segments, irrespective of the conformation, often were detached from any photoreceptor inner segment.

Figure $4 a$ demonstrates the organizational effects of PEDF on photoreceptor outer segments. The addition of $50 \mathrm{ng} / \mathrm{ml}$ of PEDF to eyes maintained in the absence of the RPE (Fig. $4 a$ ) prevented the aberrant assembly of outer segment discs that follows removal of the RPE. Nascent photoreceptor outer segments were very similar to eyes with an adherent RPE in that they were highly structured with discs of equal diameter. There were very few discontinuous membranous expanses, and individual outer segments were in line with inner segments. Multiple calycal processes surrounded, and extended beyond, the tips of the outer segments, a feature that was missing without the addition of PEDF (compare with Fig. $3 b$ ). Figure $4 b$ exemplifies the level of photoreceptor outer segment disorganization observed after the addition of anti-PEDF antibodies. In the absence of the RPE, but in the presence of both PEDF and anti-PEDF antibody $(50 \mathrm{ng} / \mathrm{ml}$ and 1:500 dilution, respectively), photoreceptor outer segments formed a staggered profile of membranes with uneven disc termination similar to that documented in eyes lacking both an RPE and the exogenous PEDF. In addition, the outer segments were detached from the corresponding inner segment.

The average organizational grade of photoreceptor outer segments under our four experimental conditions is summarized in 


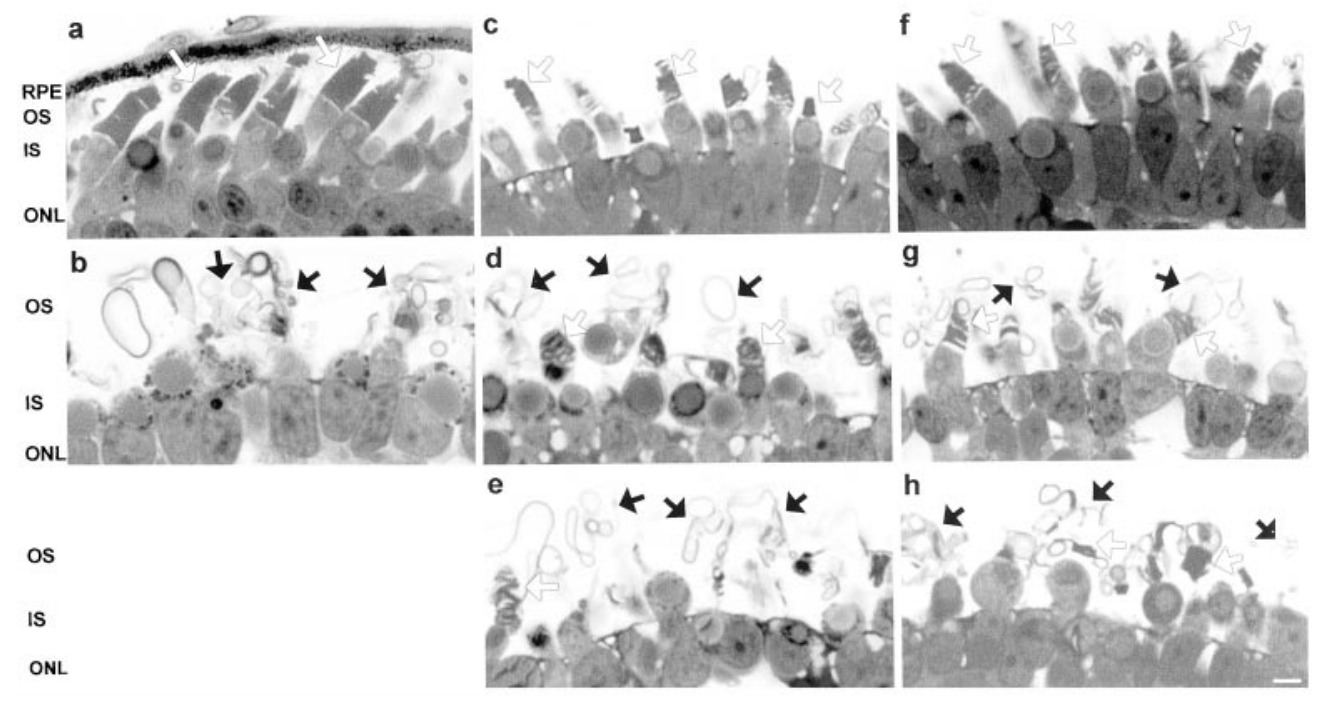

Figure 2. Outer retinal morphology under the various culture conditions used in this study. $a$, In retinas that were allowed to undergo the final stages of cytomorphogenesis in vitro with a normally apposed RPE, the outer segments are highly organized and tightly stacked, yielding individual profiles that are in line with individual photoreceptor inner segments. $b$, In retinas that were maintained in the absence of the RPE, photoreceptor outer segment membrane structure was markedly disorganized, with little evidence of normal disc stacking. $c$, The addition of $50 \mathrm{ng} / \mathrm{ml}$ of PEDF stimulated the proper folding of outer segment membranes. Increased concentrations of PEDF [i.e., $100 \mathrm{ng} / \mathrm{ml}(d)$ and $500 \mathrm{ng} / \mathrm{ml}(e)]$ failed to induce similar levels of outer segment organization in the absence of the RPE. Under these conditions the majority of photoreceptors had many whorls of membranous discs interspersed with areas of organized outer segments. $f$. Nonimmune serum (1:500 dilution) was unable to block the morphogenetic properties of PEDF, and most outer segments were highly structured. Although the addition of a 1:1000 dilution of anti-PEDF antiserum $(g)$ partially blocked the dramatic improvement in outer segment organization that was promoted by $50 \mathrm{ng} / \mathrm{ml}$ of PEDF, a 1:500 dilution of antiserum $(h)$ significantly disrupted the permissive and protective effects of $50 \mathrm{ng} / \mathrm{ml}$ of PEDF. RPE, Retinal pigment epithelium; $O S$, outer segment; $I S$, inner segment; $O N L$, outer nuclear layer. Organized outer segments are indicated by white arrows, and disorganized outer segments are marked with black arrows. Scale bar, $10 \mu \mathrm{m}$.

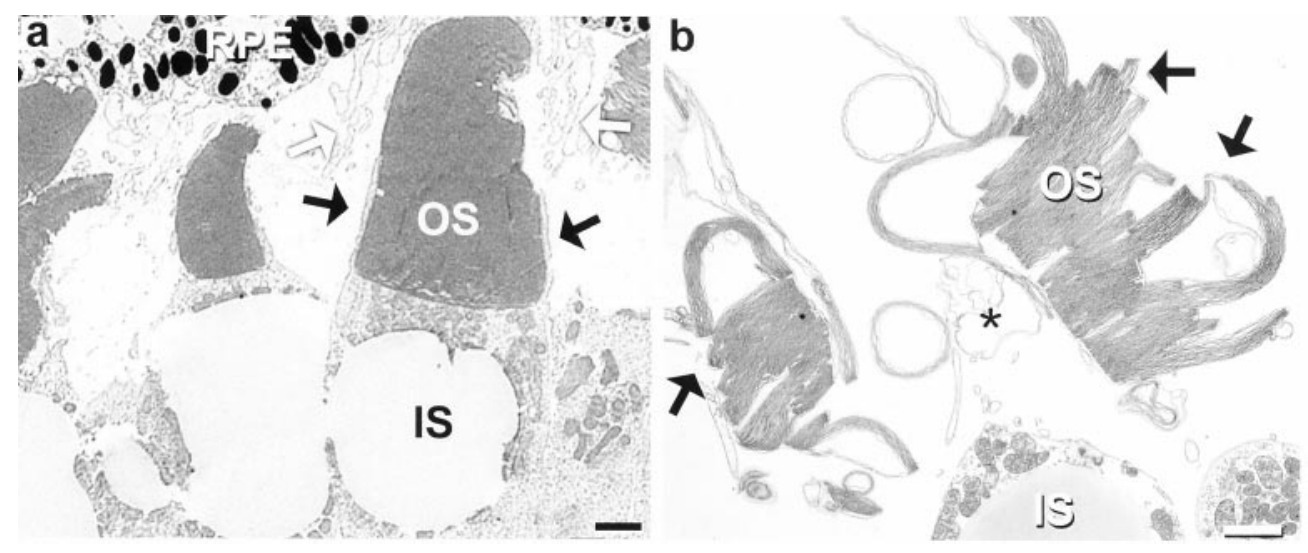

Figure 3. Ultrastructural analysis of Xenopus laevis retinas with and without an adherent RPE. $a$, In the presence of the RPE the photoreceptor outer segments were composed of an orderly array of stacked discs surrounded by a plasma membrane. The disc margins were in proper alignment, with all discs of a single photoreceptor being the same diameter. Calycal processes (black arrows) that arise from the inner segment were in close proximity to the vitreal aspect of the outer segments. The apical process of the RPE surrounded the tips of the outer segments (white arrows). $b$, In the absence of the RPE there was some organization of outer segment discs into flattened, stacked saccules; however, the diameter of outer segment discs differed greatly (black arrows), with many discs terminating prematurely. Also, areas of whorl-like membrane with minimally ordered stacked discs were present (asterisk). Calycal processes were not present. OS, Outer segment; $I S$, inner segment. Scale bar, $1 \mu \mathrm{m}$.

Figure 5. By one-way ANOVA the overall $F$ test for differences among the four groups was highly significant $(F=56.57 ; p=$ $0.0001)$. In retinas that completed morphogenesis with an adherent RPE, the vast majority of photoreceptor outer segments was highly structured, properly folded, and contained discs of equal diameter. Use of our grading scale yielded a grade of $3.958 \pm 0.200$ (mean \pm $\mathrm{SD})$ on a scale of -1 to 4 . This value indicates that nearly all of the photoreceptor outer segments that were evaluated were $100 \%$ organized. In the absence of the RPE the average grade of photoreceptor outer segment organization decreased to $1.042 \pm 1.207$ ( $p=0.0001$ compared with both control retinas with an adherent RPE and PEDF-treated eyes), indicating that, on average, only $25 \%$ of the outer segment material was organized into stacked, flattened membranous saccules. In the presence of $50 \mathrm{ng} / \mathrm{ml}$ of PEDF the average organizational grade was $3.042 \pm 1.338$, indi- cating that $\sim 75 \%$ of the outer segment membranes were highly structured. This value did not differ statistically from control retinas $(p=0.0144)$, and it was significantly greater than the organizational grade of retinas that lacked PEDF stimulation or that were exposed to the anti-PEDF antibody ( $p=0.0001$ for both comparisons). The addition of anti-PEDF antibody significantly decreased the organizational grade to $0.708 \pm 1.541$, indicating that $<20 \%$ of the outer segment material was organized ( $p=0.0001$ compared with both control retinas and those exposed to PEDF).

\section{Immunolocalization of opsin}

The patterns of opsin immunolocalization are illustrated in Figure 6. In control retinas that were allowed to mature in vitro with a normally apposed RPE, the opsin labeling was very heavy over the outer segments of the majority of photoreceptors. Unlabeled pho- 

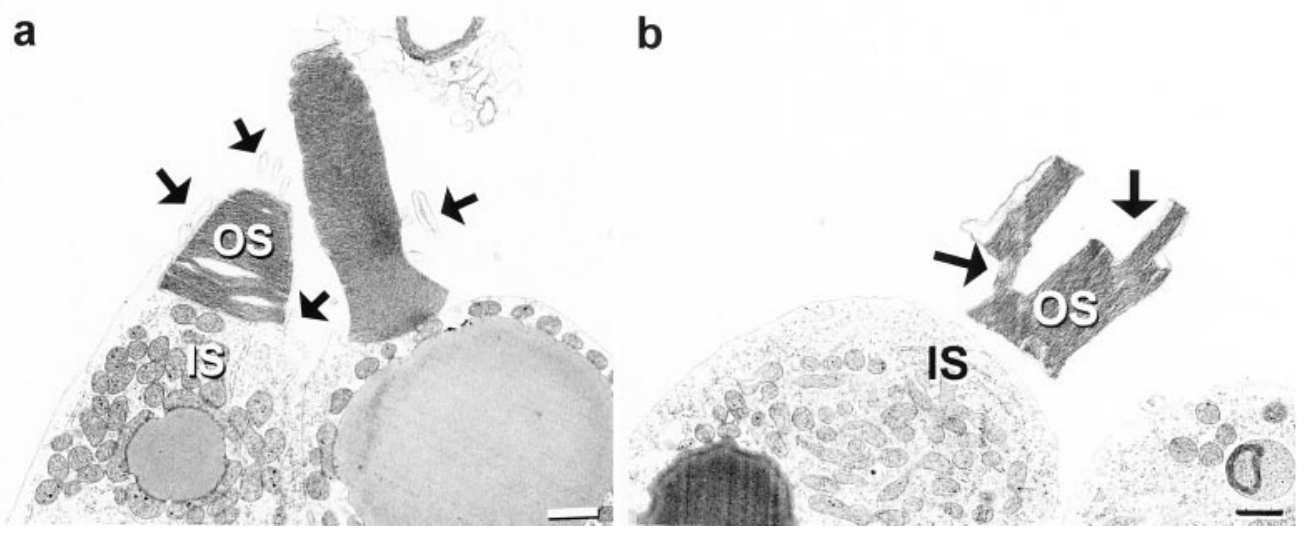

Figure 4. PEDF prevented photoreceptor degeneration after removal of the RPE. $a$, Photoreceptor outer segments were highly structured and ordered in retinas exposed to exogenous PEDF $(50 \mathrm{ng} / \mathrm{ml})$. Most discs were flattened and stacked in an orderly array and had an equal diameter. Calycal processes were present and were closely adherent to the outer segments. They extended to the tips of the outer segments, beyond their normal position (black arrows). $b$. Anti-PEDF (1:500 dilution) blocked the protective effect of PEDF. Photoreceptor outer segments no longer were composed of stacked membranous discs of similar diameter. The addition of both PEDF and anti-PEDF to retinas that lacked an adherent RPE resulted in premature termination of disc elongation and led to a staggered border of the membranous discs (black arrows). Calycal processes were not formed. OS, Outer segment; IS, inner segment. Scale bar, $1 \mu \mathrm{m}$.

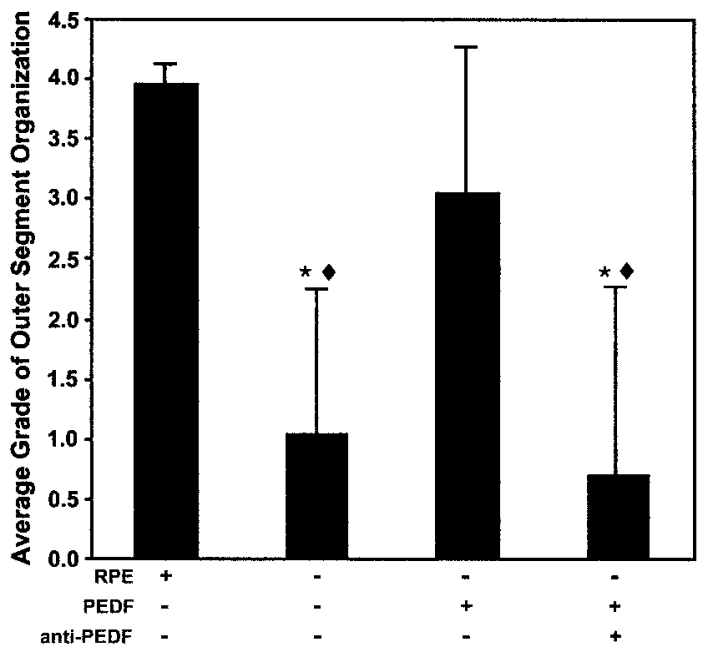

Figure 5. When allowed to complete morphogenesis in the presence of an attached RPE, the average organizational grade of individual outer segments was $3.958 \pm 0.200$ (mean $\pm \mathrm{SD}$ ) on a scale of -1 to 4 , indicating that nearly all of the photoreceptor outer segments were $100 \%$ organized. In the absence of the RPE the average grade of photoreceptor outer segment organization decreased to $1.042 \pm 1.207$ (mean $\pm \mathrm{SD} ; p=0.0001$ ), indicating that nearly $75 \%$ of the graded outer segment material was disorganized into whorl-like or staggered profiles. In the presence of $50 \mathrm{ng} / \mathrm{ml}$ PEDF the average organizational grade was $3.042 \pm 1.338$ (mean \pm SD), which is not significantly different from that obtained with photoreceptors that matured with an adherent RPE $(p=0.0144)$. This value indicates that $\sim 75 \%$ of the outer segment membranes were highly structured. In the presence of anti-PEDF (1:500 dilution) the organizational grade significantly decreased to $0.708 \pm 1.541$ (mean $\pm \mathrm{SD} ; p=0.0001$ compared with both control retinas and those exposed to PEDF), reflecting that $<25 \%$ of the outer segment material was organized. The grading scale that was used is as follows: $4=100 \%$ organization of an individual outer segment; $3=$ $75 \%$ organization of an individual outer segment; $2=50 \%$ organization of an individual outer segment; $1=25 \%$ organization of an individual outer segment; $0=0 \%$ organization of an individual outer segment; $-1=$ complete absence of outer segment membrane. Qualities of a disorganized outer segment included whorl-like and staggered profiles. $p<0.009$ is considered statistically significant. *Significantly different from control retinas with an attached RPE; $\downarrow$, significantly different from eyes exposed to PEDF.

toreceptors are presumably cones or minor rods because of the specificity of the antibody (Stiemke et al., 1994) (Fig. 6a). The labeling was very dense and evenly aligned, suggestive of organized, stacked outer segment membranes. The dysmorphogenesis of nascent outer segments, induced by the removal of the RPE, also was reflected in the immunolocalization pattern of opsin (Fig. 6b).
Opsin immunolabeling appeared to be reduced in quantity and altered in conformation. Individual outer segment profiles could not be distinguished. Patches of immunopositive label alternating with the absence of label were present distal to the inner segments, similar to the outer segment contours seen in Figures $2 b$ and $3 b$. Some areas of immunolabeling were out of the plane of focus, reflecting in three dimensions the whorls of membrane rather than the tight cylinders of outer segment that are evident in the presence of the RPE. Opsin trafficking appeared to be normal in that no opsin label was detected in other areas of the cell, including the synaptic terminus.

In the absence of the RPE, $50 \mathrm{ng} / \mathrm{ml}$ of PEDF promoted the formation of well organized outer segment membranes and allowed for normal immunolabeling patterns of opsin (Fig. 6c). In PEDFprotected retinas opsin labeling was very similar to that of control retinas. Individual outer segment profiles with linear labeling patterns were evident, consistent with the organized outer segment membrane disc lamellae that were observed morphologically (compare with Figs. $2 c, 4 a$ ). The addition of anti-PEDF (1:500 dilution) disrupted the evenly profiled opsin immunolabeling patterns that were permitted by PEDF (Fig. $6 d$ ). An uneven jagged labeling pattern was present, somewhat similar to that of photoreceptors induced to degenerate by removal of the RPE (compare with Fig. 6b).

\section{Quantitation of opsin}

Figure 7 illustrates the average levels of opsin expression detected chemifluorescently. The overall $F$ test for differences among the four groups was highly significant $(F=20.38 ; p=0.0004)$. In eyes undergoing degeneration induced by RPE removal, there was a significant decrease in the steady-state level of opsin to $\sim 70 \%$ of control retinas maintained with an adherent RPE $(p=0.0001$; Fig. $7 a, b)$. The addition of $50 \mathrm{ng} / \mathrm{ml}$ of PEDF prevented the decrease in steady-state opsin levels and allowed opsin expression to reach levels that were not significantly different from retinas maintained with an intact $\operatorname{RPE}(p=0.3938$ compared with retinas with an intact RPE; $p=0.0003$ compared with RPE-deprived retinas). When anti-PEDF was added to block the organizational effect of PEDF, a significant reduction in opsin steady-state expression to $\sim 86 \%$ of control values was noted $(p=0.0088)$. This value was not significantly different from that obtained from retinas exposed to PEDF alone $(p=0.0347)$.

\section{DISCUSSION}

Although effective medical or surgical strategies have been developed to treat very highly prevalent conditions such as cataracts, glaucoma, or diabetic retinopathy, very few therapeutic options are 
a

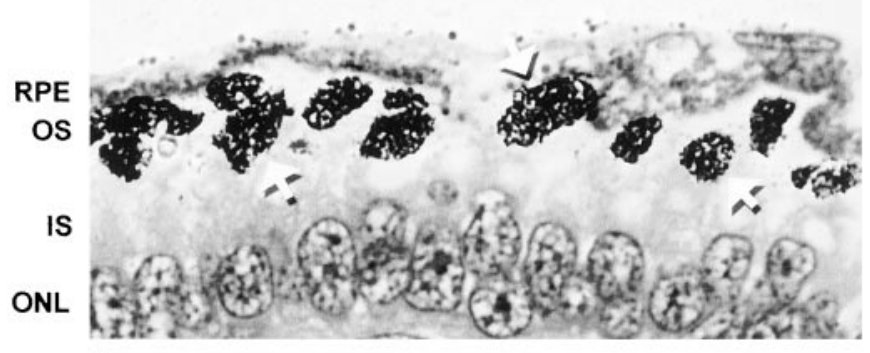

b
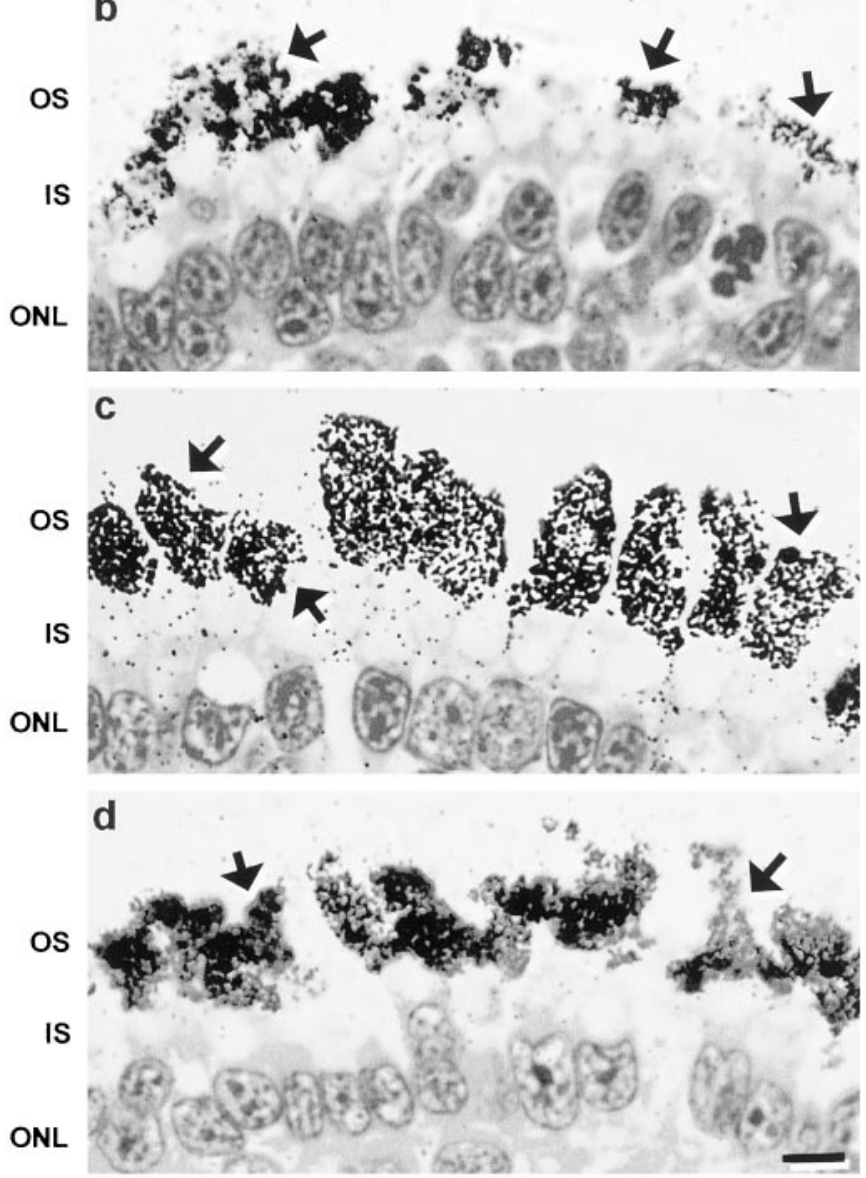

Figure 6. PEDF prevented the altered opsin immunolabeling patterns induced by the removal of the RPE. $a$, In retinas that completed morphogenesis with an adherent RPE, the opsin labeling was very heavy over photoreceptor outer segments, which was indicative of organized, stacked outer segment membranes. $b$, Removal of the RPE resulted in an altered immunolocalization pattern of opsin in which individual outer segment profiles could not be distinguished. Rather, heavy patches of label alternating with a complete lack of immunopositive label were present distal to the inner segments. $c$, In the absence of the RPE, PEDF promoted the formation of well organized outer segment membranes. Individual outer segment profiles with linear opsin immunolabeling patterns were evident consistent with the organized outer segment membrane disc lamellae that were observed morphologically. $d$, The addition of anti-PEDF disrupted the linear and evenly profiled opsin immunolabeling patterns. Rather, an uneven jagged labeling pattern was present. $R P E$, Retinal pigment epithelium; $O S$, outer segment; $I S$, inner segment. Scale bar, $10 \mu \mathrm{m}$.

available to prevent, reverse, or halt visual loss caused by retinal detachment, dysf unction linked to RPE-specific genetic mutations, or age-related macular degeneration. The evaluation of putative neuroprotective agents on animal models of retinal degeneration is fairly advanced, although the results of these studies are still somewhat controversial; therefore, direct applicability to the human condition is unclear. A landmark study by the LaVail and

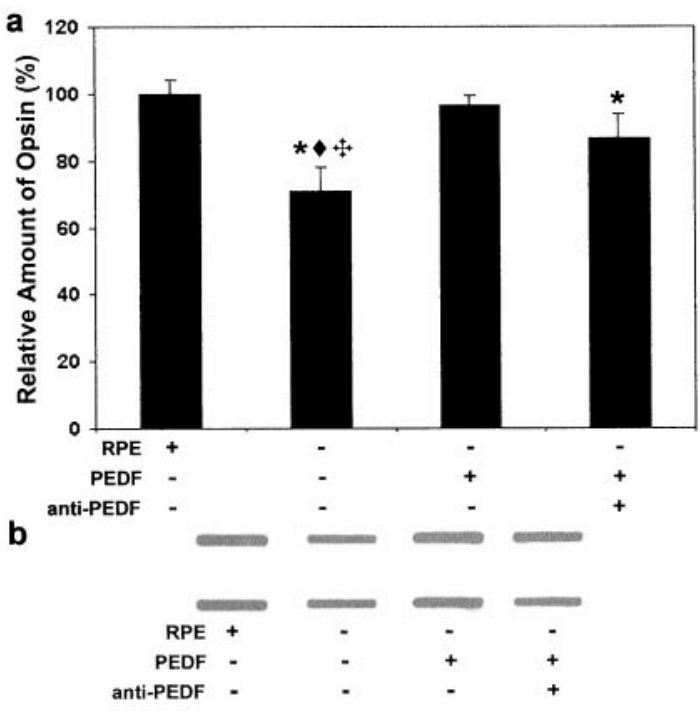

Figure 7. PEDF promoted opsin expression. $a$, Relative amounts of opsin in control, dysmorphic, and PEDF-supported photoreceptors. Values were normalized to the amounts of opsin in control retinas with an attached RPE. In the absence of the RPE the photoreceptors downregulated the expression of opsin to $70 \%$ of that synthesized in the presence of the RPE ( $p=0.0001$ ). PEDF prevented the downregulation induced by RPE detachment and sustained opsin expression $(p=0.3938$ compared with control eyes; $p=0.0003$ compared with eyes without an attached RPE). Anti-PEDF partially blocked the permissive effect of PEDF on opsin synthesis $(p=0.0088$ compared with control eyes). $p<0.009$ is considered statistically significant. * Significantly different from control retinas with an attached RPE; $\downarrow$, significantly different from eyes exposed to PEDF; + significantly different from PEDF plus anti-PEDF antibody. $b$, Representative immunoblot illustrating the differences in opsin expression under the various experimental conditions.

Steinberg groups (Faktorovich et al., 1990) was the first to indicate that growth factors normally present in the retinal microenvironment are able to rescue photoreceptors from degeneration in the RCS rat. Their work has expanded in recent years to explore the effects of multiple growth factors (or combinations thereof) on various forms of mutant rodents with inherited retinal degenerations that are similar to human mutations (LaVail et al., 1998). Their results indicate that varying degrees of rescue are achieved with some, but not all, neuroprotective agents. In addition, the effect is not universal in all mutant rodent strains. In other forms of retinal degeneration it has been documented that ciliary neurotrophic factor (Axokine) rescued photoreceptors from degeneration in the $R d y$ cat, whereas brain-derived neurotrophic factor had no effect (Chong et al., 1999). In a model of retinal detachment the brain-derived neurotrophic factor protected surviving photoreceptors and perhaps stimulated regeneration of the outer segments (Lewis et al., 1999).

$\mathrm{PEDF}$ is a $50 \mathrm{kDa}$ glycoprotein that was isolated initially from medium conditioned by human fetal RPE cells (Tombran-Tink and Johnson, 1989), but it since has shown a wider distribution in various tissues of the eye and other parts of the CNS (Ortego et al., 1996; Tombran-Tink et al., 1996). PEDF has not, however, been demonstrated to be present in cells of the neural retina (Tombran-Tink et al., 1995). The PEDF gene shares structural and sequence homology with members of the serpin gene family, yet inhibitory activity has not been associated with its function and little homology is seen between the conserved active domain of most serpins and PEDF (Becerra et al., 1995). Morphological and biochemical changes evident in neuronal precursor cells after treatment with PEDF include extensive neurite outgrowths and the upregulation of neuron-specific enolase and neurofilament proteins. Numerous studies have documented physiological functions of PEDF in a variety of tissues, including protection of retinal neurons against hydrogen peroxide-induced 
cell death (Cao et al., 1999); promotion of the survival of cultured cerebellar granule cells (Taniwaki et al., 1995); delay of photoreceptor cell death in mouse models of hereditary retinal degenerations (Cayouette et al., 1999); and protection against glutamate-induced neurotoxicity of motor neurons (Bilak et al., 1999), cerebellar granule cells (Taniwaki et al., 1997), and hippocampal neurons (DeCoster et al., 1999). In addition, PEDF differentially protects immature, but not mature, cerebellar neurons against apoptosis (Araki et al., 1998). More recently, PEDF has been demonstrated to be a major component of the ocular vitreous and aqueous humor where it has been implicated as a potent inhibitor of angiogenesis (Dawson et al., 1999).

The PEDF glycoprotein is secreted in abundance by the RPE cells into the interphotoreceptor matrix where it binds to glycosaminoglycans that fill the extracellular space between photoreceptor outer segments and the RPE (Tombran-Tink et al., 1995; Wu et al., 1995), placing this molecule in a prime physical location to affect the underlying neural retina and in particular the photoreceptors. The functional role of PEDF in retinal development and histogenesis is not fully known. Although it has been demonstrated that PEDF is synthesized early in human development (i.e., 17 weeks in gestation; Tombran-Tink et al., 1995), its precise role for its early expression is yet to be delineated. In addition, the gene for PEDF has been tightly linked to the RP13 locus on the short arm of chromosome 17 (17p13.3), implicating it as a candidate gene for one form of autosomal dominant retinitis pigmentosa (TombranTink et al., 1994; Goliath et al., 1996). The disease manifestations in this retinal degeneration are reported to be consistently aggressive, with restricted visual fields and night blindness as early as four years of age (for review, see online source: Mendelian Inheritance in Man. http://www.ncbi.nlm.nih.gov/omim/). This is somewhat uncommon for an autosomal dominant disease. In retinitis pigmentosa caused by rhodopsin mutation this phenomenon is observed more commonly with mutations that disrupt molecular pathways of critical relevance to photoreceptor function and survival (Iannaccone, 1998).

In the present study we document for the first time that PEDF exerts a very powerful morphogenetic effect on photoreceptors. At the time of removal from the embryo to culture the photoreceptors had not yet completed morphogenesis. Therefore, virtually all outer segment membranous material was elaborated while in culture under all of the experimental conditions (Stiemke et al., 1994). We predict that in our experimental preparation the removal of the RPE cells eliminated the source of PEDF for retinal photoreceptor cells. The lack of PEDF stimulation affected negatively the photoreceptor development. Supplementation of the medium with exogenous PEDF $(50 \mathrm{ng} / \mathrm{ml})$ closely mimicked the presence of the RPE and supported the final stages of photoreceptor cytogenesis. PEDF permitted the assembly of photoreceptor nascent outer segment membranes into stacked, flattened membranous saccules surrounded proximally by calycal processes. In addition, it stimulated photoreceptor protein expression, as measured by means of opsin quantification.

The average level of outer segment organization in PEDFtreated retinas was significantly greater than in RPE-deprived ones and not significantly different from control retinas, although in absolute quantitative terms it was attenuated somewhat. These findings, along with the effect on opsin expression levels, are especially important on biological grounds. It is well established that the integrity of the photoreceptor outer segment is indispensable for vision to take place and that disorganization of the outer segment is associated with degeneration of that same photoreceptor cell and loss of sight. Indeed, a disruption of photoreceptor outer segments is common to both human (Green et al., 1985; Farber et al., 1987; Rodrigues et al., 1987; Birnbach et al., 1994; Li et al., 1994, 1995; Milam et al., 1998; Green, 1999) and animal models (LaVail et al., 1972, 1975, 1982, 1985; LaVail and Sidman, 1974; LaVail and Mullen, 1976a,b; Edwards and Szamier, 1977; Carter-Dawson et al., 1978; LaVail, 1979; Travis et al., 1989, 1991; Narfström et al., 1991; Pittler and Baehr, 1991; Ma et al., 1995;
Cheng et al., 1997; Kohl et al., 1998; Kennedy et al., 1999; Redmond et al., 1999) of various types of retinal degenerations. Although the organization of the outer segment is critical, other studies have demonstrated that visual acuity can be preserved despite some loss of photoreceptors. Elegant psychophysical experiments by Geller et al. (1992) have demonstrated that $75 \%$ integrity of the sampling elements across degenerate arrays leaves grating visual acuity completely intact. The ability of the human eye to compensate for significant losses of photoreceptors before a measurable drop in visual acuity occurs was also noted previously by Sandberg and Berson (1983). By analogy, our results suggest that the organizational effects of PEDF on photoreceptor outer segments may allow for the preservation of an intact visual potential in treated retinas. Notwithstanding the differences between our experimental conditions and the in vivo state, the potential therapeutic implications of this observation are self-evident. Our results may be extended to support the plausible use of PEDF as a therapeutic option to protect against photoreceptor degeneration induced by retinal detachment in addition to various dystrophic conditions of the RPE.

In summary, our results demonstrate the critical role PEDF plays during the final stages of photoreceptor morphogenesis. We have demonstrated that PEDF prevented the dysmorphic photoreceptor changes that were induced by RPE removal. Under these experimental conditions exogenously added PEDF supported normal levels of opsin expression and permitted the proper assembly of nascent outer segment membranes in RPE-deprived, but otherwise intact, eyes from Xenopus laevis embryos.

\section{REFERENCES}

Anderson DH, Guérin CJ, Erickson PA, Stern WH, Fisher SK (1986) Morphological recovery in the reattached retina. Invest Ophthalmol Vis Sci 27:168-183.

Araki T, Taniwaki T, Becerra SP, Chader GJ, Schwartz JP (1998) Pigment epithelium-derived factor (PEDF) differentially protects immature but not mature cerebellar granule cells against apoptotic cell death. J Neurosci Res 53:7-15.

Becerra SP, Sagasti A, Spinella P, Notario V (1995) Pigment epitheliumderived factor behaves like a noninhibitory serpin. J Biol Chem 270:25992-25999.

Bilak MM, Corse AM, Bilak SR, Lehar M, Tombran-Tink J, Kuncl RW (1999) Pigment epithelium-derived factor (PEDF) protects motor neurons from chronic glutamate-mediated neurodegeneration. J Neuropathol Exp Neurol 58:719-728.

Birnbach CD, Järveläinen M, Possin DE, Milam AH (1994) Histopathology and immunocytochemistry of the neurosensory retina in fundus flavimaculatus. Ophthalmology 101:1211-1219.

Cao W, Tombran-Tink J, Chen W, Mrazek D, McGinnis JF (1999) Pigment epithelium-derived factor protects cultured retinal neurons against hydrogen peroxide-induced cell death. J Neurosci Res 57:789-800.

Carter-Dawson LD, LaVail MM, Sidman RL (1978) Differential effect of the $r d$ mutation on rods and cones in the mouse retina. Invest Ophthalmol Vis Sci 17:489-498.

Cayouette M, Smith SB, Becerra SP, Gravel C (1999) Pigment epitheliumderived factor delays the death of photoreceptors in mouse models of inherited retinal degenerations. Neurobiol Dis 6:523-532.

Cheng T, Peachey NS, Li S, Goto Y, Cao Y, Naash MI (1997) The effect of peripherin $/ r d s$ haploinsufficiency on rod and cone photoreceptors. J Neurosci 17:8118-8128.

Chong NHV, Alexander RA, Waters L, Barnett KC, Bird AC, Luthert PJ (1999) Repeated injections of a ciliary neurotrophic factor analogue leading to long-term photoreceptor survival in hereditary retinal degeneration. Invest Ophthalmol Vis Sci 40:1298-1305.

Dawson DW, Volpert OV, Gillis P, Crawford SE, Xu H-J, Benedict W, Bouck NP (1999) Pigment epithelium-derived factor: a potent inhibitor of angiogenesis. Science 285:245-248.

D'Cruz PM, Yasumura D, Weir J, Matthes MT, Abderrahim H, LaVail MM, Vollrath D (2000) Mutation of the receptor tyrosine kinase gene Mertk in the retinal dystrophic RCS rat. Hum Mol Genet 9:645-651.

DeCoster MA, Schabelman E, Tombran-Tink J, Bazan NG (1999) Neuroprotections by pigment epithelial-derived factor against glutamate toxicity in developing primary hippocampal neurons. J Neurosci Res 56:604-610.

Edwards RB, Szamier RB (1977) Defective phagocytosis of isolated rod outer segments by RCS rat retinal pigment epithelium in culture. Science 197:1001-1003.

Erickson PA, Fisher SK, Anderson DH, Stern WH, Borgula GA (1983) Retinal detachment in the cat: the outer nuclear and outer plexiform layers. Invest Ophthalmol Vis Sci 24:927-942. 
Faktorovich EG, Steinberg RH, Yasumura D, Matthes MT, LaVail MM (1990) Photoreceptor degeneration in inherited retinal dystrophy delayed by basic fibroblast growth factor. Nature 347:83-86.

Farber DB, Flannery JG, Bird AC, Shuster T, Bok D (1987) Histopathological and biochemical studies on donor eyes affected with retinitis pigmentosa. In: Degenerative retinal disorders: clinical and laboratory investigations (Hollyfield JG, Anderson RE, LaVail MM, eds), pp 53-67. New York: Liss.

Gaur VP, Liu Y, Turner JE (1992) RPE conditioned medium stimulates photoreceptor cell survival, neurite outgrowth, and differentiation in vitro. Exp Eye Res 54:645-659.

Geller AM, Sieving PA, Green DG (1992) Effect of grating identification of sampling with degenerate arrays. J Opt Soc Am [A] 9:472-477.

Goliath R, Tombran-Tink J, Rodriques R, Chader GJ, Rajkumar R, Greenberg J (1996) The gene for PEDF, a retinal growth factor, is a prime candidate for retinitis pigmentosa and is tightly linked to the RP13 locus on chromosome $17 \mathrm{p} 13.3$. Mol Vis 2:5.

Green W (1999) Histopathology of age-related macular degeneration. Mol Vis 5:27.

Green WR, McDonnell PJ, Yeo JH (1985) Pathologic features of senile macular degeneration. Ophthalmology 92:615-627.

Gu SM, Thompson DA, Srikumari CR (1997) Mutations in RPE65 cause autosomal recessive childhood-onset severe retinal dystrophy. Nat Genet 17:194-197.

Guérin CJ, Anderson DH, Fariss RN, Fisher SK (1989) Retinal reattachment of the primate macula. Invest Ophthalmol Vis Sci 30:1708-1725.

Guérin CJ, Lewis GP, Fisher SK, Anderson DH (1993) Recovery of photoreceptor outer segment length and analysis of membrane assembly rates in regenerating primate photoreceptor outer segments. Invest Ophthalmol Vis Sci 34:175-183

Hollyfield JG, Rayborn ME (1979) Photoreceptor outer segment development: light and dark regulate the rate of membrane addition and loss. Invest Ophthalmol Vis Sci 18:117-133.

Hollyfield JG, Witkovsky P (1974) Pigmented retinal epithelium involvement in photoreceptor development and function. J Exp Zool 189:357-378.

Iannaccone A (1998) Phenotypical differences in autosomal dominant retinitis pigmentosa associated with distinct rhodopsin mutations. Exp Eye Res 67:S235.

Jablonski MM, Ervin CS (2000) A closer look at lactose-mediated support of retinal morphogenesis. Anat Rec 259:205-214.

Jablonski MM, Wohabrebbi A, Ervin CS (1999) Lactose promotes organized photoreceptor outer segment assembly and preserves expression of photoreceptor proteins in retinal degeneration. Mol Vis 5:16.

Jacobson AG (1967) Amphibian cell culture, organ culture, and tissue dissociation. In: Methods in developmental biology (Wilt FH, Wessells NK, eds), pp 531-542. New York: Crowell.

Kancherla V, Kedzierski W, Travis GH, Jablonski MM (1999) Abnorma formation of outer segments in Xenopus laevis eye rudiments cultured with $r d s$ antisense oligonucleotides. In: Retinal degenerative diseases and experimental therapy (Hollyfield JG, Anderson RE, LaVail MM, eds), pp 419-429. New York: Plenum.

Kennedy BN, Saari JC, Crabb JW (1999) CRALBP and inherited retina degeneration. In: Retinal degenerative diseases and experimental therapy (Hollyfield JG, Anderson RE, LaVail MM, eds), pp 43-53. New York: Plenum.

Kohl S, Giddings I, Besch D, Apfelstedt-Sylla E, Zrenner E, Wissinger B (1998) The role of the peripherin $/ r d s$ gene in retinal dystrophies. Acta Anat (Basel) 162:75-84.

LaVail MM (1979) The retinal pigment epithelium in mice and rats with inherited retinal degeneration. In: The retinal pigment epithelium (Zinn KM, Marmor MF, eds), pp 357-380. Cambridge: Harvard UP.

LaVail MM, Mullen RJ (1976a) Role of the pigment epithelium in inherited retinal degeneration analyzed with experimental mouse chimeras. Exp Eye Res 23:227-245.

LaVail MM, Mullen RJ (1976b) Studies on the etiology of inherited retinal degeneration in mice and rats using experimental chimeras. In Structure of the eye III (Yamada E, Mishima S, eds), pp 363-369. Tokyo: Japan Journal of Ophthalmology.

LaVail MM, Sidman RL (1974) C57BL/6J mice with inherited retina degeneration. Arch Ophthalmol 91:394-400.

LaVail MM, Sidman RL, O’Neil DA (1972) Photoreceptor-pigment epithelial cell relationships in rats with inherited retinal degeneration. Radioautographic and electron microscope evidence for a dual source of extra lamellar material. J Cell Biol 53:185-209.

LaVail MM, Sidman RL, Gerhardt CO (1975) Congenic strains of RCS rats with inherited retinal dystrophy. J Hered 66:242-244.

LaVail MM, Yasumura D, Gorrin G, Pinto LH (1982) The interphotoreceptor matrix in RCS rats: possible role in photoreceptor cell death. In: Problems of normal and genetically abnormal retinas (Clayton RM, Haywood J, Reading HW, Wright A, eds), pp 215-222. New York: Academic

LaVail MM, Yasumura D, Hollyfield J (1985) The interphotoreceptor matrix in retinitis pigmentosa: preliminary observations from a family with an autosomal dominant form of disease. In: Retinal degeneration experimental and clinical studies (LaVail MM, Hollyfield JG, Anderson RE, eds), pp 51-62. New York: Liss.
LaVail MM, Yasumura D, Matthew MT, Lau-Villacorta C, Unoki K, Sung C-H, Steinberg RH (1998) Protection of mouse photoreceptors by survival factors in retinal degenerations. Invest Ophthalmol Vis Sci 39:592-602.

Lewis GP, Erickson PA, Anderson DH, Fisher SK (1991) Opsin distribution and protein incorporation in photoreceptors after experimental retinal detachment. Exp Eye Res 53:629-640.

Lewis GP, Linberg KA, Geller SF, Guérin CJ, Fisher SK (1999) Effects of the neurotrophin brain-derived neurotrophic factor in an experimental model of retinal detachment. Invest Ophthalmol Vis Sci 40:1530-1544.

Li L, Turner JE (1991) Optimal conditions for long-term photoreceptor cell rescue in RCS rats: the necessity for healthy RPE transplants. Exp Eye Res 52:669-679.

Li ZY, Jacobson SG, Milam AH (1994) Autosomal dominant retinitis pigmentosa caused by the threonine-17-methionine rhodopsin mutation: retinal histopathology and immunocytochemistry. Exp Eye Res 58:397-408.

Li ZY, Kljavin I, Milam AH (1995) Rod photoreceptor neurite sprouting in retinitis pigmentosa. J Neurosci 15:5430-5438.

Lolley RN, Farber DB, Rayborn ME, Hollyfield JG (1977) Cyclic GMP accumulation causes degeneration of photoreceptor cells: simulation of an inherited disease. Science 196:664-666.

Ma J, Norton JC, Allen AC, Burns JB, Hasel KW, Burns JL, Sutcliffe JG, Travis GH (1995) Retinal degeneration slow $(r d s)$ in mouse results from simple insertion of a haplotype-specific element into protein-coding exon II. Genomics 28:212-219.

Marlhens F, Bareil C, Griffoin JM, Zrenner E, Amalric P, Eliaou C, Liu SY, Harris E, Redmond TM, Arnaud B, Claustres M, Hamel CP (1997) Mutations in RPE65 cause Leber's congenital amaurosis. Nat Genet 18:311-312.

Maw MA, Kennedy B, Knight A, Bridges R, Rothe KE, Mani EJ, Kuddadan JK, Nancarrow D, Crabb JW, Denton MJ (1997) Mutations of the gene encoding cellular retinaldehyde-binding protein in autosomal recessive retinitis pigmentosa. Nat Genet 17:198-200.

Milam AH, Li ZY, Fariss RN (1998) Histopathology of the human retina in retinitis pigmentosa. Prog Retin Eye Res 17:175-205.

Narfström K, Nilsson SE, Wiggert D, Kutty G, Chader GJ, van Veen T (1991) Hereditary rod cone degeneration in the Abyssinian cat: morphological and immunocytochemical aspects. In: Retinal degenerations (Anderson RE, Hollyfield JG, LaVail MM, eds), pp 51-60. Boca Raton, FL: CRC.

Nieuwkoop PD, Faber J (1956) Normal table of Xenopus laevis (Daudin). Amsterdam: North-Holland.

Ortego J, Escribano J, Becerra SP, Coca-Prados M (1996) Gene expression of the neurotrophic pigment epithelium-derived factor in the human ciliary epithelium. Invest Ophthalmol Vis Sci 37:2759-2767.

Papermaster D, Dreyer W (1974) Rhodopsin content in the outer segment membranes of bovine and frog retinal rods. Biochemistry 13:2438-2444.

Pittler SJ, Baehr W (1991) Identification of the precise molecular defect responsible for blindness in the mouse retinal degeneration mutant, $r d$. In: Retinal degenerations (Anderson RE, Hollyfield JG, LaVail MM, eds), pp 455-465. Boca Raton, FL: CRC.

Redmond TM (1999) The RPE65-deficient mouse as a model for RPE65associated Leber's congenital amaurosis and related disorders. In: Retinal degenerative diseases and experimental therapy (Hollyfield JG, Anderson RE, LaVail MM, eds), pp 35-42. New York: Plenum.

Rodrigues MM, Bardenstein D, Wiggert B, Lee L, Fletcher RT, Chader G (1987) Retinitis pigmentosa with segmental massive retinal gliosis. An immunohistochemical, biochemical, and ultrastructural study. Ophthalmology 94:180-186.

Röhlich P, Adamus G, McDowell JH, Hargrave PA (1989) Binding pattern of anti-rhodopsin monoclonal antibodies to photoreceptor cells: an immunocytochemical study. Exp Eye Res 49:999-1013.

Sandberg MA, Berson EL (1983) Visual acuity and cone spatial density in retinitis pigmentosa. Invest Ophthalmol Vis Sci 24:1511-1513.

Sheedlo HJ, Linxi L, Turner JE (1992) Effects of RPE cell factors secreted from permselective fibers on retinal cells in vitro. Brain Res 587:327-337.

Sheedlo HJ, Nelson TH, Lin N, Rogers TA, Roque RS, Turner JE (1998) RPE secreted proteins and antibody influence photoreceptor cell survival and maturation. Brain Res Dev Brain Res 107:57-69.

Sokal RR, Rohlf FJ (1995) Replicated tests of goodness of fit. In: Biometry (Sokal RR, Rohlf FJ, eds), pp 229-240. New York: Freeman.

Stiemke MM, Hollyfield JG (1994) Outer segment disc membrane assembly in the absence of the pigment epithelium: the effect of exogenous sugars. Dev Brain Res 80:285-289.

Stiemke MM, Hollyfield JG (1995) Effect of sugars on photoreceptor outer segment assembly. In: Degenerative diseases of the retina (Anderson RE, Hollyfield JG, LaVail MM, eds), pp 129-137. New York: Plenum.

Stiemke MM, Landers RA, Al-Ubaidi MR, Hollyfield JG (1994) Photoreceptor outer segment development in Xenopus laevis: influence of the pigment epithelium. Dev Biol 162:169-180.

Taniwaki T, Becerra SP, Chader GJ, Schwartz JP (1995) Pigment epithelium-derived factor is a survival factor for cerebellar granule cells in culture. J Neurochem 64:2509-2517.

Taniwaki T, Hirashima N, Becerra SP, Chader GJ, Etcheberrigaray R, 
Schwartz JP (1997) Pigment epithelium-derived factor protects cultured cerebellar granule cells against glutamate-induced neurotoxicity. J Neurochem 68:26-32.

Tombran-Tink J, Johnson LV (1989) Neuronal differentiation of retinoblastoma cells induced by medium conditioned by human RPE cells. Invest Ophthalmol Vis Sci 30:1700-1707.

Tombran-Tink J, Chader GJ, Johnson LV (1991) PEDF: a pigment epithelial-derived factor with potent neuronal differentiative activity. Exp Eye Res 53:411-414.

Tombran-Tink J, Swaroop A, Rodrigues I, Chader GJ (1994) Localization of the gene for pigment epithelium-derived factor (PEDF) to chromosome $17 \mathrm{p} 13.1$ and expression in cultured human retinoblastoma cells Genomics 19:266-272.

Tombran-Tink J, Shivaram SM, Chader GJ, Johnson LV, Bok D (1995) Expression, secretion, and age-related downregulation of pigment epithelium-derived factor, a serpin with neurotrophic activity. J Neurosci 15:4992-5003.

Tombran-Tink J, Rodrigues IR, Chung D, Linker T, Englander E, Chader GJ (1996) Organization, evolutionary conservation, expression and unusual Alu density of the human gene for pigment epithelium-derived factor, a unique neurotrophic serpin. Mol Vis 2:11.

Travis GH, Brennan MB, Danielson PE, Kozak CA, Sutcliffe JG (1989) Identification of a photoreceptor-specific mRNA encoded by the gene responsible for retinal degeneration slow $(r d s)$. Nature 338:70-73.

Travis GH, Sutcliffe JG, Bok D (1991) The retinal degeneration slow (rds) gene product is a photoreceptor disc membrane-associated glycoprotein. Neuron 6:61-70.

Wu YQ, Notario V, Chader GJ, Becerra SP (1995) Identification of pigment epithelium-derived factor in the interphotoreceptor matrix of bovine eyes. Protein Expr Purif 6:447-456. 